\title{
The short answer is "more"
}

Published at www.cmaj.ca on Oct. 13

$\mathrm{M}$ ore money, more "implementation" aid and research, as well as more of a concerted international effort to tackle the explosive growth in the incidence of noncommunicable diseases in the developing world - all have fast emerged as the three central themes of the World Health Summit in Berlin, Germany.

The call for more money is, of course, a universal and ubiquitous demand.

The call for more support for "implementation" appears to be a response to demands from developing countries that local health system structures, capabilities and needs must be taken into more account in the delivery of global health programs.

Meanwhile, the call for paying more attention to chronic, cardiovascular and pulmonary diseases, as well as mental health, is a prelude to the 2011 Summit on Non-Communicable Diseases that the United Nations has convened, at which some form of global fund is expected to be created.

The trio has surfaced in session after session of the summit as delegates explored such issues as containing the spread of infectious diseases, the global burden of obesity and diabetes, medical curricula, the impact of climate change on health, and even, "space physiology and medicine."

They've even surfaced in the several of the summit's keynote lectures, including one in which Dr. Francis Collins, director of the United States National Institutes of Health (NIH), argued that the academic and research communities have both a "greater opportunity and a greater responsibility" to become more active in transforming bench science into drugs, vaccines and other medical products that are useful in the developing world.

To that end, Collins said that US President Barack Obama's recently announced US\$63-billion, six-year

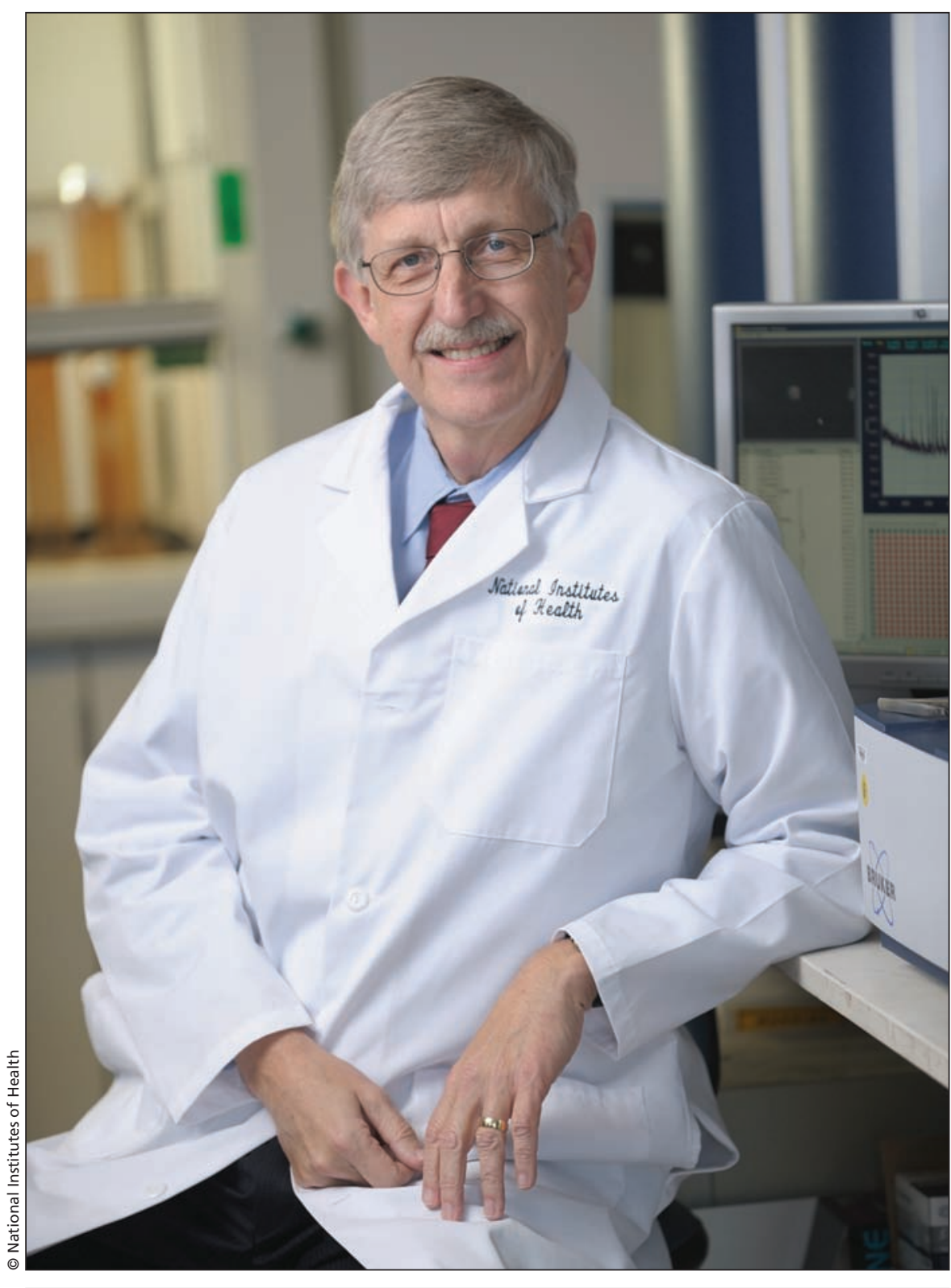

Academic and research communities have a "greater opportunity and a greater responsibility" to become more active in transforming bench science into drugs, vaccines and other medical products that are useful in the developing world, said Dr. Francis Collins, director of the United States National Institutes of Health.

Global Health Initiative is aimed at redressing the problem of delivering health care in a way that accounts for the differences in developing countries' health systems (www.whitehouse .gov/the_press_office/Statement-by-the -President-on-Global-Health-Initiative/).
"It clearly is an area of greater need," Collins said.

In a similar vein, Collins said the NIH has become involved with the US\$130-million program funded by the US President's Emergency Plan for AIDS Relief that is designed to develop 
the research capability of African universities and increase the number of health care workers that they train.

It is all part and parcel of what Collins called a responsibility of the academic world to become more involved in "implementation" research that strengthens local institutions and health systems in developing countries.

Collins later told a press conference that implementation research must encompass a measure of work on health systems, as well as measures to improve the efficacy of local interventions, such as the recently announced Global Alliance for Clean Cookstoves, which seeks to reduce the projected two million deaths that are annually caused by exposure to smoke from traditional cookstoves and open fires (www.cmaj.ca /cgi/doi/10.1503/cmaj.109-3692).

"Clearly, there's many people who are concerned that our global research agenda has been a little too academic," Collins said. "If it's going to benefit people in low-income countries, then it will have to be applied at scale. It really does require some degree of health systems participation."

Others argued that global health programs have paid nowhere near enough attention to the adequacy of health human resources in the developing world.
In sub-Saharan Africa, for example, there are only two physicians and only 11 nurses and midwives, per 10000 population, noted Luis Sambo, the World Health Organization's regional director for Africa. "There's also a drain of staff from rural to urban areas," he said, adding that "health staff regularly abandon the health sector to go and work in jobs in other sectors that pay better."

Global health programs cannot possibly meet their targets if local health systems are incapable of, for example, administering vaccines at a local level, Sambo said during a panel discussion on means of reducing child and maternal mortality rates.

There's also a need for more "innovations in community delivery platforms," such as involving women's groups in instructing pregnant women about making healthier choices, such as giving birth in the presence of trained health care workers, and even directly paying women small sums of money to deliver in facilities, said Dr. Zulfiqar Ahmed Bhutta, chairman of the Aga Khan University in Pakistan.

Meanwhile, delegates from virtually every part of the world have repeatedly argued that the industrialized world has all but ignored noncommunicable diseases. They have frequently cited recent
United Nations projections that as many as 388 million people will die of a chronic noncommunicable disease, such as chronic cardiovascular conditions (primarily heart disease and stroke), chronic respiratory conditions and type 2 diabetes, in the next 10 years. The UN estimates that $80 \%$ of those chronic-disease deaths will occur in low- and middle-income countries.

Other keynote lectures included an update on the state of climate change research by Hans Joachim Schellnhuber, director of Germany's Potsdam Institute for Climate Impact Research, who argued that evidence of the detrimental health effects of global warming are already being felt, in the form of the 11000 deaths that occurred this summer as a result of the heat wave in Russia, and the 1600 deaths that occurred as result of the floods in Pakistan.

If, as some climate change experts project, the average global air temperature rises seven or eight degrees, health challenges will include ones stemming from a rise in water levels, "such as saltwater intrusion and 500 million people who will have to find a new home. ... Which countries are going to take them?" Schellnhuber asked. Wayne Kondro, CMAJ

DOI:10.1503/cmaj.109-3698 